\title{
PHARMACOVIGILANCE IN INDIA: PERSPECTIVES AND PROSPECTS
}

\author{
* Kumar Sumit, Baldi Ashish \\ Department of Quality Assurance, I.S.F. College of Pharmacy, Moga, Punjab, India-142001 \\ *Corresponding author'sE-mail:baldiashish@gmail.com
}

\begin{abstract}
:
In the scenario of ever-increasing range and potency of medicines, safety of medicines is one of the key parameters along with therapeutic efficacy for success of any drug. India is now a preferred clinical trials destination for to be launched drug entities. By keeping in view the increasing incidences, dug related mortality, proper identification, reporting, evaluation and understanding of adverse drug reaction lead to development of pharmacovigilance. It is a branch of pharmacological science critical to effective clinical practices and public health with immense capability for growth. These necessities the utmost need of effective regulations for drug approval and conscious pre and post approval vigilance of undesired effect especially in India. This article summarized aims objectives and methodologies used in pharmacovigilance with a critical overview of existing pharmacovigilance system in India, challenges to overcome and future prospects with respect to Indian context.

Key-words: Adverse drug reaction, Clinical trial, Drug safety, Pharmacovigilance, Post marketing surveillance.
\end{abstract}

\section{Introduction}

Clinical research industry has grown around the world at an unbelievable rate in the past few years. The main survival point of the pharmaceutical industry is innovation and for introducing new drugs in the market, the companies have to conduct clinical trials as per ICH GCP guidelines as well as guidelines of the country where trial is planned. Pharmacovigilance is an important and integral part of clinical research. Both clinical trials safety and post marketing pharmacovigilance are critical throughout the product lifecycle especially in ensuring the safety. 1 According to the World Health Organization, pharmacovigilance is defined as the science and activities relating to the detection, assessment, understanding and prevention of adverse effects or any other possible drugrelated problem, particularly long term and short term adverse effects of medicines. ${ }^{2}$ Systematic pharmacovigilance is essential to build up reliable information on the safety of all category medicines for the development of appropriate guidelines for safe effective use. It basically involves identification and evaluation of safety signals. Some of the frequently used terms are defined in Table 1.

Table 1: Definitions of terms related to pharmacovigilance

\begin{tabular}{|c|c|c|}
\hline Term & Definition & Ref \\
\hline Adverse event & $\begin{array}{l}\text { An adverse event is defined as any un toward medical occurrence that may present during } \\
\text { treatment with a drug but which does not necessarily have a relationship with its use. }\end{array}$ & 4 \\
\hline $\begin{array}{l}\text { Adverse drug } \\
\text { reaction }\end{array}$ & $\begin{array}{l}\text { An adverse drug reaction (ADR) is any noxious, unintended and undesired effect of a drug, } \\
\text { which occurs at a dose used in human for prophylaxis, diagnosis, therapy or modification of } \\
\text { physiological function. }\end{array}$ & 6 \\
\hline $\begin{array}{l}\text { Post marketing } \\
\text { surveillance }\end{array}$ & $\begin{array}{l}\text { Post-marketing surveillance (PMS) is the practice of monitoring the safety of } \\
\text { a pharmaceutical drug or device after it has been released in the market. }\end{array}$ & 7 \\
\hline Clinical trials & $\begin{array}{l}\text { Clinical trials are sets of tests in medical research and drug development that generate safety } \\
\text { and efficacy data (or more specifically, information about adverse drug reactions and } \\
\text { adverse effects of other treatments) for health interventions (e.g., drugs, diagnostics, } \\
\text { devices, therapy protocols). }\end{array}$ & 9 \\
\hline Safety signals & $\begin{array}{l}\text { Safety signal refer to a concern about an excess of adverse events compared to what would } \\
\text { be expected to be associated with products use, which can arise from post marketing data } \\
\text { and other sources, such as pre clinical data and events associated with other products in the } \\
\text { same pharmacological class. }\end{array}$ & 11 \\
\hline
\end{tabular}

Pharmacovigilance has constantly grown in importance in last 10 years, relating to absolute amount of adverse drug reactions (ADRs) and to the fact that several hospital admissions are due to ADR with considerable social costs. The ADR percentage detected as preventable ranges from $35 \%$ to $50 \%$, with implicit rejections on the social welfare. 3 Therefore, a strong need was felt to monitor the effect of drugs after its launch in the market i.e., post marketing surveillance. The practice of science of pharmacovigilance emerged after well known thalidomide tragedy of the 1960 's which led to the development of the first spontaneous reporting system of ADRs. ${ }^{4}$ Major incidences of drug induced toxicity reported across the globe are given in Table 2 . 
Table 2: Examples of major induced toxicities, reported in post marketing surveillance

\begin{tabular}{llll}
\hline Year & Drug & Toxicity & Remark \\
\hline $\mathbf{1 9 5 0}$ & Chroramphenicol & Aplastic anemia & Still continued \\
$\mathbf{1 9 6 1}$ & Thalidomide & Phocomelia & National disaster \\
$\mathbf{1 9 7 0}$ & Clioquinol & SMON & After 30 years of use \\
$\mathbf{1 9 7 0}$ & Diethylstilbestrol & Adenocarcinoma of the cervix & In utero exposure \\
$\mathbf{1 9 7 5}$ & Practolol & Oculo-mucocutaneous & 5 years after marketing \\
& & syndrome & \\
$\mathbf{1 9 7 6}$ & Zomepirac & Anaphylaxis & Withdrawn \\
$\mathbf{1 9 7 8}$ & Phenformin & Lactic acidosis & Withdrawn \\
$\mathbf{1 9 8 0}$ & Ticrynafen & Deaths from liver & Detected after 5 years of suspection \\
& & Disease & \\
$\mathbf{1 9 8 2}$ & Ticrynafen & Hepatitis & Withdrawn \\
$\mathbf{1 9 9 0}$ & Etretinate & Birth defect & High risk of birth-defect, narrow therapeutic index \\
$\mathbf{1 9 9 9}$ & Astimizole & Arrhythmias & Because of interaction with other drugs \\
$\mathbf{2 0 0 4}$ & Rofecoxib & Myocardial infarction & Withdrawn \\
$\mathbf{2 0 0 7}$ & Inhaled insulin & Long term safety, high cost & Withdrawn in the UK due to poor sales caused by national \\
& & & restriction on prescribing, doubts over long term safety. \\
$\mathbf{2 0 1 0}$ & Rosiglitazone & Heart attacks & Withdrawn in Europe \\
$\mathbf{2 0 1 1}$ & Drotrcogin alfa & Prowess -shock study & Withdrawn by Lily \\
$\mathbf{2 0 1 2}$ & Rimonabant & Depression, risk of suicidal & Withdrawn \\
$\mathbf{2 0 1 2}$ & Sibutramine & tendencies and seizures & \\
\hline
\end{tabular}

\section{Aims of Pharmacovigilance}

Pharmacovigilance is the science of collecting, monitoring, researching, assessing and evaluating information from healthcare providers, pharmaceutical companies and patients on the adverse effects of medications, biologicals, herbal and traditional medicines. Pharmacovigilance is used in different sectors as shown in Fig. 1.

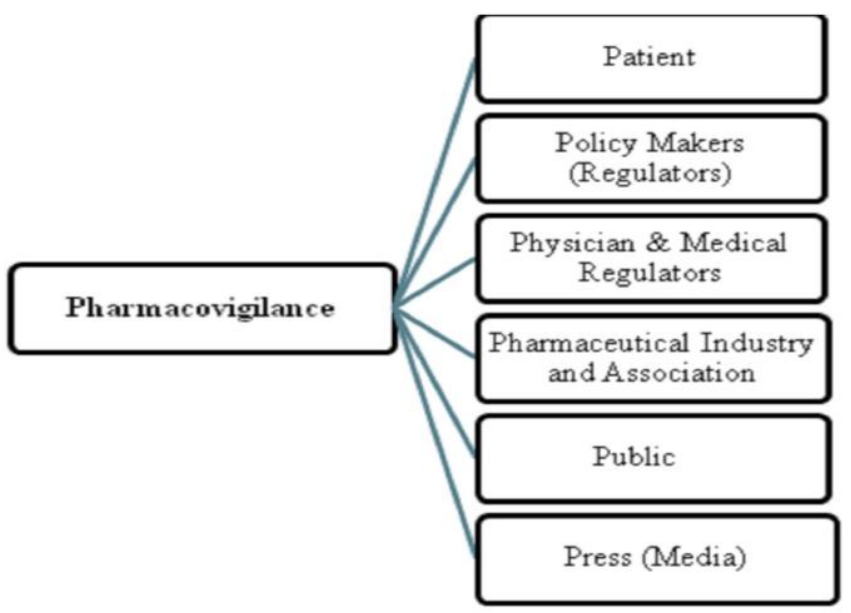

Figure 1: Pharmacovigilance in different sectors.

Pharmacovigilance involves monitoring and assessing the quality of drugs along with detection and prevention of any adverse effect of drugs with following objectives: ${ }^{5}$

- To identify new information about hazards associated with medicines.

- To prevent harm to the patients.

- To improve patient care and safety in relation to the use of medicines, and all medical and paramedical interventions.

- To improve public health and safety in relation to the use of medicines.
- To contribute to the assessment of benefit, harm, effectiveness and risk of medicines, encouraging their safe, rational and more effective (including costeffective).

- To promote understanding, education and clinical training in pharmacovigilance and its effective communication to health professionals and the public. ${ }^{6}$

- To identify risk factors and possible mechanisms underlying adverse reactions.

- To estimate quantitative aspects of benefit/risk analysis and dissemination of information needed to improve drug prescribing and regulation.

\section{Role of Pharmacovigilance}

The role of pharmacovigilance is to check the safety monitoring in clinical trials involves collecting adverse events, laboratory investigations and details of the clinical examination of patients. Pharmacovigilance staff may be involved to varying degrees in all phases of clinical trials, including the planning, execution, data analysis and reporting of safety. ${ }^{7}$ Pharmacovigilance approve the drug regulatory authorities needs to go further than the approval of new medicines, to encompass a wider range of issues relating to the safety of medicines, namely:

- Clinical trials;

- The safety of complementary and traditional medicines, vaccines and biological medicines;

- The receipt, processing and reporting of adverse event reports;

- Following-up with reporters to obtain further details about a case report;

- Providing an information service to healthcare professionals and patients on product safety; and

- Providing safety expertise to internal cross-functional colleagues. 
Pharmacovigilance programmes need to maintain strong links with the drug regulatory authorities to ensure that the latter are well briefed on safety issues in everyday clinical practice, whether these issues are relevant to future regulatory action or to concerns that emerge in the public domain. ${ }^{8}$ On the other, regulators need to understand the specialized and pivotal role that pharmacovigilance plays in ensuring the ongoing safety of medicinal products.

\section{Pharmacovigilance of Herbal Medicines}

Now a day's herbal medicine are very popular in general public but the safety of these remedies are major issue for public health. The use of herbs in traditional medicines continues to expand rapidly across the world. ${ }^{9}$ In various national health-care settings for the health of the patients, herbal products have a very large share almost prescribed medicines. However, mass media reports of adverse events tend to be sensational and give a negative impression regarding the use of herbal medicines in general rather than identifying the causes of these events, which may relate to a variety of issues. ${ }^{10}$ Monitoring of herbal safety but require modification to address specific challenges such as botanical nomenclature, quality, adulteration, labeling issues, prescriber/reporter differences and under-reporting. ${ }^{11}$

\section{Pharmacovigilance Methods}

As per International Conference on Harmonization Efficacy Guidelines 2 (ICHE2E) guidelines, the pharmacovigilance methods can be categorized as:

\section{Passive surveillance}

(a) Spontaneous reporting system (SRS)

(b) Case series

\section{Stimulated reporting}

Active surveillance

(a) Sentinel sites

(b) Drug event monitoring

(c) Registries

Comparatives observational studies

(a) Cross sectional study

(b) Case control study

(c) Cohort study

Targeted clinical investigations

\section{Descriptive studies}

(a) Natural history of disease

(b) Drug utilization study

Pharmacovigilance methods can be also classified as hypothesis generation methods and hypothesis testing method as follows:

\section{Hypothesis generating methods}

(a) Spontaneous ADR reporting

(b) Prescription event monitoring

\section{Hypothesis testing methods}

(a) Case control study

(b) Cohort studies

(c) Randomized controlled trials
Most frequently used methods for monitoring of drug safety are as follows:

\subsection{Spontaneous reporting systems}

Recording and reporting clinical observations of a suspected ADR with a marketed drug is known as spontaneous or voluntary reporting. ${ }^{12}$ There are subtle differences between countries but the principles are the same. The national system based on this in the UK is the 'Yellow Card' scheme, where doctors, dentists, and recently, hospital pharmacists are encouraged to report all suspected reactions to new medicines and serious suspected reactions to established medicines. Safety of medicines is commonly monitored through spontaneous reporting systems. ${ }^{\mathbf{1 3}}$ Standardized forms are used for reporting of suspected adverse reactions to the regulatory authorities by medical professionals, including physicians, pharmacists, nurses and in some countries, by consumers. The reports are of 'suspected' adverse reactions, and a reporter does not have to confirm the association between drug and effect. ${ }^{14}$

Spontaneous reports are more likely to be effective where products are regulated as medicines and also where products are supplied by health professionals, who are well informed in the use of this reporting system. Consumers may not be aware of the importance of reporting adverse effects. ${ }^{15}$ Spontaneous reporting of adverse drug reaction and adverse events is an important tool for gathering the safety information for early detection, case reports collected by such system represent the source of information providing the lowest level of evidence and highest level of uncertainty regarding casualty. ${ }^{16}$ Spontaneous reporting has advantages in that it is available immediately after a new product is marketed, continues indefinitely and covers all patients receiving the drug. It is the most likely method of detecting new, rare ADRs and frequently generates safety signals which need to be examined further. ${ }^{17}$ The main limitations are the difficulty in recognizing previously unknown reactions, particularly events that are not usually thought of as being ADRs and under-reporting, which is variable, sensitive to reporting stimuli and difficult to quantify. It usually does not confirm hypotheses; although situations exist where spontaneous reporting data alone allow conclusions that a signal indeed represents a true ADR. ${ }^{18}$

\subsection{Prescription-event monitoring (PEM)}

PEM is a non-interventional, observational cohort form of pharmacovigilance. PEM studies are cohort studies where exposure is obtained from a centralised service and outcomes from simple questionnaires completed by general practitioners. 19 Follow-up forms are sent for selected events. Because PEM captures all events and not only the suspected ADRs, PEM cohorts potentially differ in respect to the distribution of number of events per person depending on the nature of the drug under study. This variance can be related either with the condition for which the drug is prescribed (e.g. a condition causing high morbidity will have, in average, a higher number of events per person compared with a condition with lower morbidity) or with the drug effect itself. ${ }^{20}$

\subsection{Targeted Clinical Investigations (TCI)}




\section{Sumit et al}

Journal of Drug Delivery \& Therapeutics; 2013, 3(4), 237

When significant risks are identified from pre-approval clinical trials, further clinical studies might be called for evaluate the mechanism of action for the adverse reaction. In some instances, pharmacodynamics and pharmacokinetics studies might be conducted to determine whether a particular dosing instruction can put patients at an increase risk of adverse events. Genetic testing can also provide clues about which group of patients might be at an increased risk of adverse reactions. Furthermore specific studies to investigate potential drug-drug interactions and food-drug interactions needs to be conducted based on the pharmacological properties and the expected use of the drug in general practice. These studies can include population pharmacokinetic studies and drug concentration monitoring in patients and normal volunteers.

\section{Pharmacovigilance: Reporting and Functioning}

To fulfil the pharmacovigilance obligations for its marketed products as per regulations, a pharmaceutical company in India has to essentially carry out activities such as collection, included expedited reporting of serious unexpected adverse reactions and preparations. ${ }^{21}$

A typical setup for pharmacovigilance studies, people involved on various levels, organizational units and their functions are given as Fig. 2.

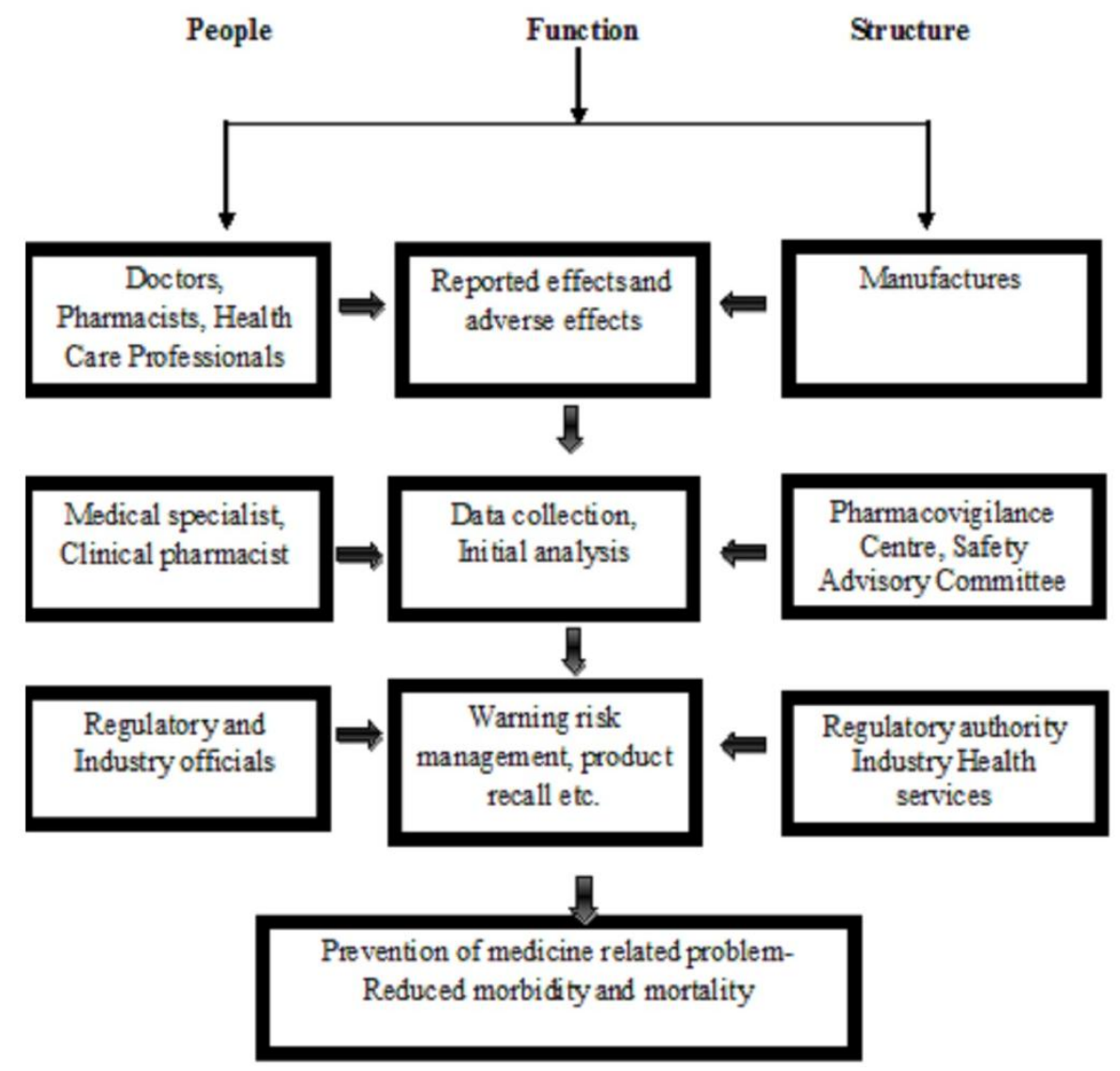

Figure 2: A typical pharmacovigilance setup: People involved, functions and structure

\subsection{Detection and reporting}

Physician has most important role to play in pharmacovigilance. Not merely because he is the first person to whom the patient will come with symptoms; but also to suspect an ADR. ${ }^{22}$ A healthcare professional or marketing authorization holder reports a suspected adverse drug reaction related to one or more medicinal products, to a national competent authority (pharmacovigilance centre). Reports are made in writing (e.g. using report forms), by telephone, electronically, or by any other approved way. ${ }^{23}$ Reports are collected and validated by the pharmacovigilance centre and are usually entered into a database. Serious reactions should be handled with the highest priority. The database is used to identify potential signals and analyze data in order to clarify risk factors, apparent changes in reporting profiles etc. ${ }^{24}$. A typical ADR reporting form is given as Fig. 3.

\subsection{Case report collection and validation}

This concerns the collection and validation of primary data i.e. the data transmitted from the reporter to the competent authority. For the validation and management of electronically transmitted reports, the specific operational procedure should be followed. ${ }^{25} \mathrm{~A}$ pharmacovigilance spontaneous report concerns a single case; one patient, one identifiable reporter, one or more suspected reactions, and one or more suspect medicinal products. According to European Directives and Regulations, only serious cases reported by healthcare professionals will be received on an expedited basis. ${ }^{26}$ 
Suspected Adv erse Drug Keaction Keporting Form

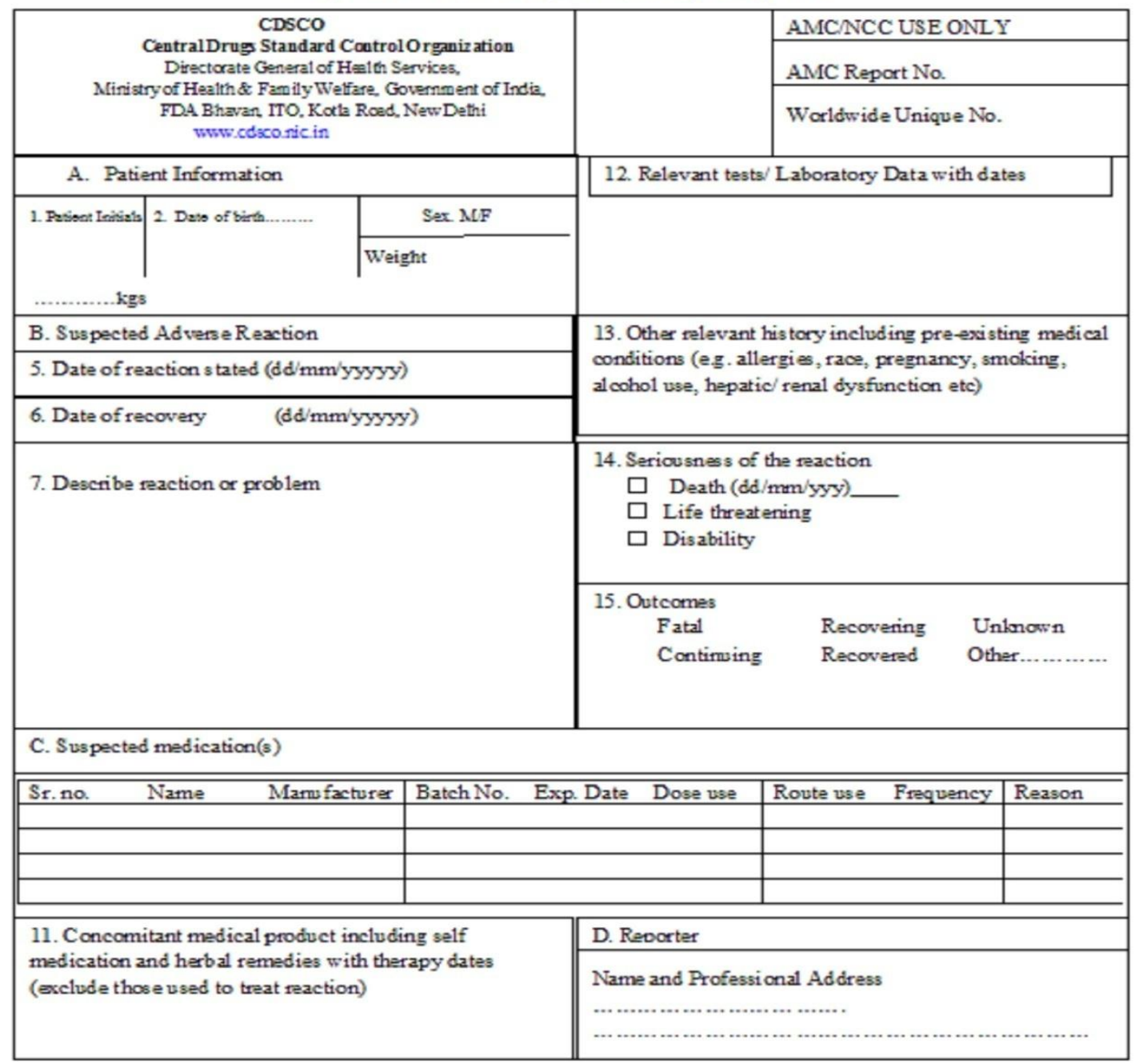

Figure 3: ADR reporting form.

\section{Clinical Trials in India}

\subsection{India: A preferred destination for clinical trials}

Global pharmaceutical companies have found India's clinical research space and opportunity very attractive ${ }^{27}$. India born CROs were able to offer the advantages of understanding the Indian scenario better, provide services at more competitive costs, and having better knowledge ${ }^{28}$ of Investigator sites in the country compared to the newer entrants in the market. India's existing favourable regulatory framework and regulations with international standards, increasing awareness of good clinical practice guidelines and its implementation by clinicians are some of the main reasons propelling the growth of clinical research in India. ${ }^{29}$ The average annual report of clinical trials conducted in India is shown as Fig. 4. ${ }^{30}$

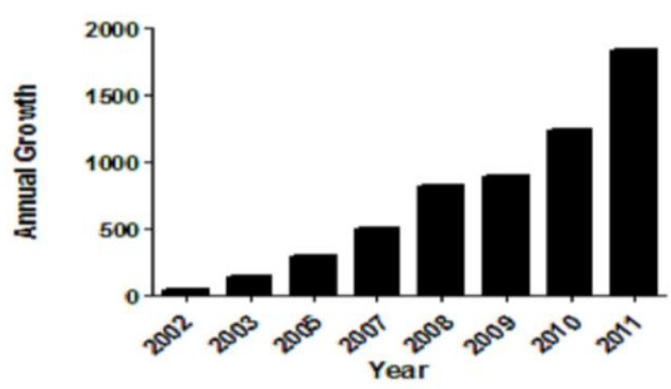

Figure 4: Growth of clinical trials in India. ${ }^{30}$
The therapeutic areas wise distribution of clinical trials and availability of diverse patient population across major therapeutic segments such as oncology, metabolic, neurology etc. in India is shown in Fig. 5. ${ }^{31}$

Some of the advantages that India offers as clinical trials destination are as follows:

- High degree of compliance to international guidelines such as the ICH GCP and the regulations lay down by the US Food and Drug Administration.

- Availability of well qualified, English speaking research professionals including physicians.

- Ongoing support and cooperation from the government.

- Lower cost compared to the west. ${ }^{32}$

- Increasing prevalence of illnesses common to both developed and developing countries.

- Availability of good infrastructure.

- Changes in Patent Laws since January 2005.

As per a recent report from FICCI, scientific feasibility, medical infrastructure, clinical trial experience, regulations, commercialization potential and cost competitiveness are some of the growth drivers responsible for the metamorphosis of Indian clinical research in the recent past. ${ }^{33}$ 


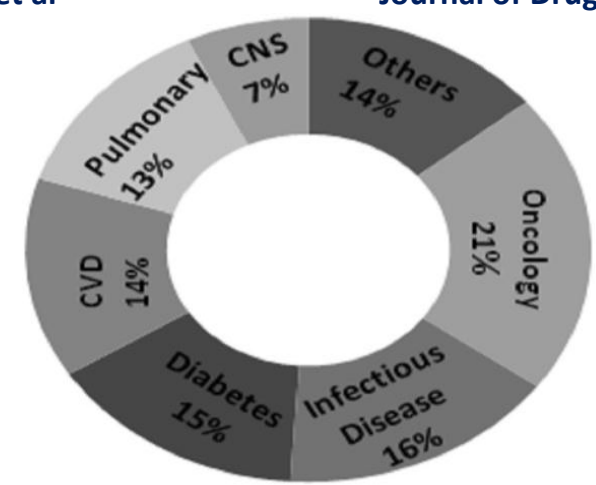

Figure 5: Therapeutic area wise distribution of clinical trials outsourced to India.

\subsection{SWOT Analysis of Indian Clinical Trial Sector}

\section{Strengths}

- Large population of over 1.2 billion, about $16 \%$ of the world's population.

- Huge pharmaceutical and biotech industry base with availability of skilled persons.

- $3^{\text {rd }}$ largest players in the world with 500 different APIs.

- Current by account for $8 \%$ of global pharmaceutical production, being $4^{\text {th }}$ in the world. ${ }^{34}$

- Conducive initiatives to harness innovative capability by government.

- Possibility of huge data mining related to safety profile of drugs due to large population. $^{35}$

Weaknesses
- As per 2009-10 estimates, expenditure on health sector was $2.1 \%$ or the total budget and $0.35 \%$ of the GDP of India. ${ }^{\mathbf{3 6}}$

- Developed countries like United States, France, Switzerland and Germany, spent around $16 \%, 11 \%$, $10.8 \%$ and $10.4 \%$ of their GDP respectively.

- Less funding available for implementation of programs and issues of national importance such as pharmacovigilance. $^{37}$

\section{Opportunities}

- Indian population is the largest source of the human biodiversity.

- Consisting of 4635 culturally and anthropologically well-defined populations, representing a perfect model to study efficacy, disease susceptibility, etiology, molecular pathology, and safety profile of drugs with respect to genetic diversity.

- Excellent potential for skilled human resources required for an effective pharmacovigilance system due to $>300,>230$ dental, $>830$ pharmacy and $>650$ recognized nursing colleges in India. ${ }^{38}$

\section{Threats}

- Under reporting of ADRs.

- Low availability of funds.

- Less ADRs monitoring centers.

8. Agencies Involved for Clinical Research Regulation In India

Various agencies of India with their prominent role in overseeing clinical trial along with Ethics committee are given in Table 3 . $^{39}$

Table 3: Roles of various regulatory agencies

\begin{tabular}{|c|c|}
\hline Agencies & Role of agencies \\
\hline Drug Controller General of India (DCGI) & Implementation the National Pharmacovigilance Program (NPP) in India. \\
\hline Central Drugs Standard Control & Operate under the supervision of the National Pharmacovigilance Advisory \\
\hline Organization (CDSCO) & $\begin{array}{l}\text { Committee to recommend procedures and guidelines for regulatory } \\
\text { interventions. }\end{array}$ \\
\hline Department of Biotechnology (DBT) & $\begin{array}{l}\text { Provides product evaluation and validation through support for limited and } \\
\text { large scale field trials for agriculture products and clinical trials for health } \\
\text { care products. }\end{array}$ \\
\hline $\begin{array}{l}\text { Ministry of Environment \& Forests } \\
\text { (MOEF) }\end{array}$ & $\begin{array}{l}\text { PAC (Project advisory committee) approves guidelines for making data } \\
\text { entries of the information provided by the environmental experts through the } \\
\text { field trials for agriculture products and clinical trials for health care products. }\end{array}$ \\
\hline Indian Council of Medical Research & Brought out the 'Policy Statement on Ethical \\
\hline (ICMR) & $\begin{array}{l}\text { Considerations involved in Research on Human Subjects' in } 1980 \text { and } \\
\text { revised these guidelines in } 2000 \text { as the 'Ethical guidelines for Biomedical } \\
\text { Research on Human Subjects'. }\end{array}$ \\
\hline Central Bureau of Narcotics (CBN) & $\begin{array}{l}\text { Closely monitored all clinical trials, which require additional narcotics } \\
\text { compliances relating to storage, import-export quotas and movement of the } \\
\text { investigational drug. }\end{array}$ \\
\hline $\begin{array}{l}\text { Ministry of Health and Family Welfare } \\
\text { (MHFW) }\end{array}$ & $\begin{array}{l}\text { An autonomous body for setting of standards for drugs, pharmaceuticals and } \\
\text { healthcare devices and technologies in India. }\end{array}$ \\
\hline National Pharmacovigilance Advisory & To collate, analyze and archive adverse drug reaction data for creating \\
\hline Committee (NPAC) & $\begin{array}{l}\text { healthy environment for the regulatory authorities to analyze the drug to be } \\
\text { marketed in India. }\end{array}$ \\
\hline
\end{tabular}




\section{Pharmacovigilance in India 9.1 The need}

Although clinical trials in India being conducted and started around 1996 in global market, the landmark year for the industry was 2005. The studies of the clinical trials are structured, supervised where the safety and efficacy of a new drug or therapy are tested in an effort to develop new treatments that will help those afflicted with the targeted condition. For conducting global clinical trials, India is looked upon as a better choice. ${ }^{40}$ India clinical market provides an opportunity of availability of large patient populations, highly educated talent, a wide spectrum of disease, lower costs of operations, and a favourable economic and intellectual property environment.

In the current time, clinical research industry has grown around the world at an unbelievable rate with pharmaceutical industry. The main survival amount of the pharmaceutical companies is innovation through introducing new drugs in the market. ${ }^{41}$ For approval, well organized, supervised and structured clinical trials have to be essentially conducted as per ICH GCP guidelines in accordance with defined rules of the country in which trial is planned. ${ }^{42}$ It is very essential as the conditions under which patients are studied during the pre-marketing phase do not necessarily reflect the way the medicine will be used in the hospital or in general practice once it is marketed. ${ }^{43}$

\section{$9.2 \quad$ The development}

India joined the World Health Organization (WHO) Adverse Drug Reaction Monitoring Programme based in Uppsala, Sweden in 1997. For the monitoring of ADR's three main centres were identified, mainly based in teaching hospitals: a National Pharmacovigilance Centre located in the Department of Pharmacology, All India Institute of Medical Sciences (AIIMS), New Delhi and two WHO special centers in Mumbai (KEM Hospital) and Aligarh (JLN Hospital, Aligarh Muslim University). ${ }^{44}$ The ADRs of the medicines which are in market for sell in OTC counter are monitored by these centers. This attempt was unsuccessful and hence, again from the $1^{\text {st }}$ of January 2005, the WHO-sponsored and World Bank-funded National Pharmacovigilance Program for India was formulated. ${ }^{45}$ The National Pharmacovigilance Program established in January 2005, was to be overseen by the National Pharmacovigilance Advisory Committee based in the Central Drugs Standard Control Organization (CDSCO), New Delhi. Two zonal centers-the South-West zonal centre (located in the Department of Clinical Pharmacology, Seth GS Medical College and KEM located in the Department of Pharmacology, AIIMS, New Delhi), were also established to collate information from all over the country and send it to the Committee as well as to the Uppsala Monitoring centre in Sweden. ${ }^{46}$ The chronological developments in the field of pharmacovigilance with special reference to India are given as Table 4 .

Table 4: Chronological developments in pharmacovigilance sector with special reference to India

\begin{tabular}{ll}
\hline Year & Event \\
\hline 1747 & First reported clinical trials by James Lind, proving the effectiveness of lemon juice in preventing scurvy \\
1937 & Death of 107 children due to sulfanilamide toxicity \\
1950 & Apalstic anemia reported due to chloramphenicol \\
1961 & Global disaster due to thalidomide toxicity \\
1963 & $16^{\text {th }}$ World Health Assembly recognize important to rapid action on ADR's \\
1968 & WHO pilot research project for international drug monitoring \\
1996 & Clinical trials of global standards started in India \\
1997 & India joined WHO Adverse Drug Reaction Monitoring Program \\
1998 & Pharmacovigilance initiated in India \\
2002 & 67 \\
$2004-05$ & National Pharmacovigilance Program launched in India \\
2005 & Conduct of structured clinical trials in India \\
$2009-10$ & PVPI initiated \\
\hline
\end{tabular}

\subsection{Pharmacovigilance Program of India (PVPI)}

Organizational structure of pharmacovigilance program of India and respective responsibilities of are given as Fig. $6 .{ }^{47}$

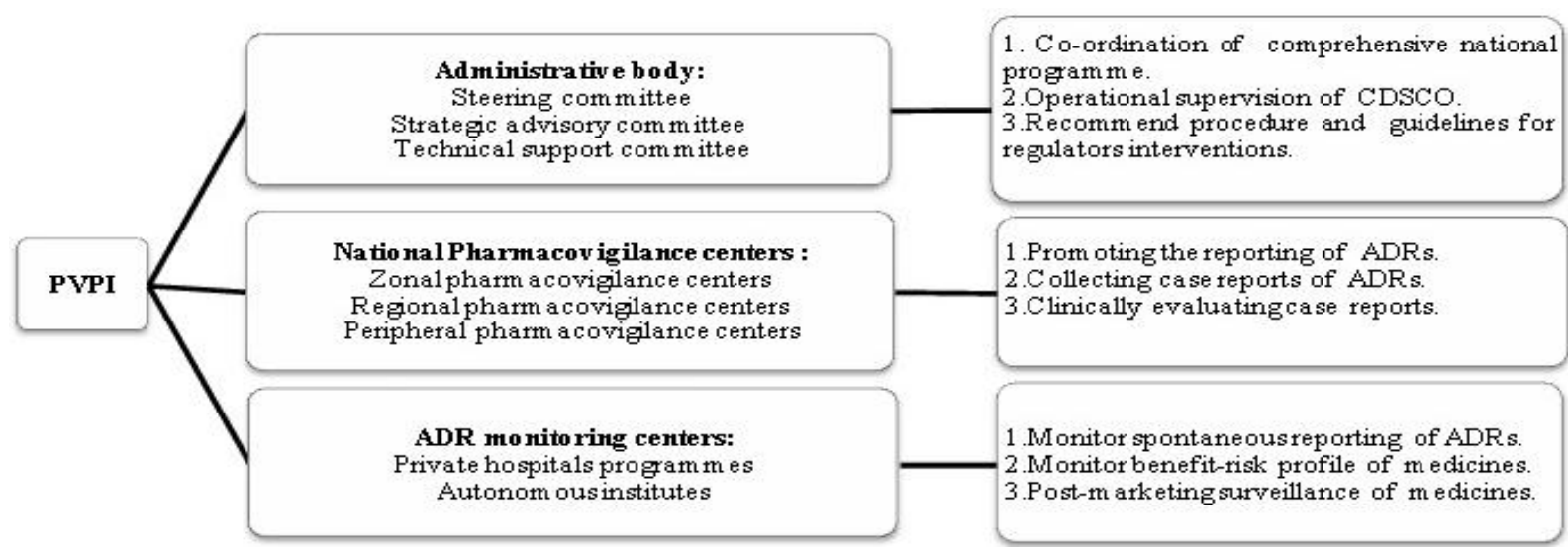

Figure 6: Pharmacovigilance program in India and responsibilities. 


\subsection{Formulation of India's pharmacovigilance guideline}

Globally, many countries have formulated their own pharmacovigilance guidelines with the aim to have a systematic process of safety reporting. The ICH has six guidelines pertaining to various aspects of drug safety: ${ }^{48.49}$

E2A- Clinical Safety Data Management: Definitions and standards for expedited reporting,

E2B- Clinical Safety Data Management: Data elements for transmission of individual case safety reports,

E2C- Clinical Safety Data Management: Periodic safety update reports for marketed drugs,

E2D- Post-approval Safety Data Management: Definitions and standards for expedited reporting,

E2E-Pharmacovigilanve planning, and

E2F- Development Safety Update Report

The USFDA has title 21 of Code of Federal Regulations (mainly part 312-Investigational New Drug and part 314Applications for FDA Approval to Market a New Drug) and the EMEA has entire Volume 9A for pharmacovigilance in humans. ${ }^{50}$ In contrast, India has only a small section of Schedule Y dedicated to drug safety, which when viewed in light of contemporary global practice, seems to have many lacunae. It is thus a felt need that CDSCO must formulate a detailed pharmacovigilance guideline. Such guideline shall incorporate all relevant areas of pre and post marketing safety, address to current lacunae and bring about clarity on issues as discussed above. Most importantly, the guidelines shall be in tune with the current international norms, so as to support India's growth as any participant in multinational clinical trials. ${ }^{51}$

\subsection{International Collaborations}

The principle of international collaboration in the field of pharmacovigilance is the main basis for the WHO International Drug Monitoring Programme, through which over 100 member nations have systems in place that encourage healthcare personnel to record and report adverse effects of drugs in their patients.

The Uppsala Monitoring Centre (UMC), located in Uppsala, Sweden, is the field name for the WHO Collaborating Centre for International Drug Monitoring. The UMC works by collecting, assessing and communicating information from member countries national pharmacovigilance programs in regards to the benefits, harm, effectiveness and risks of drugs. ${ }^{52}$

The Council for International Organizations of Medical Sciences (CIOMS), through its Working Groups, is a globally-oriented think tank that provides guidance on drug safety related problems. CIOMS is part of WHO and prepares reports are used as a reference for developing future drug regulatory policy and procedures.

\subsection{The challenges}

ADRs are one of the leading causes of death. Most of the time, these dangerous events could and should have been avoided. Despite the fact that more adverse reactions occur in patients 60 or older, the odds of suffering a ADRs really begin to increase even before age 50. Almost half (49.5\%) of Food and Drug Administration (FDA) reports of deaths from ADRs and $61 \%$ of hospitalizations from ADRs were in people younger than 60. The risk of a ADRs is about $33 \%$ higher in people aged 50 to 59 than it is in people aged 40 to 49 . Patients admitted to medical wards of a hospital found that although for $3.8 \%$ of hospital admissions, ADRs led directly to hospitalization, 57\% of these ADRs were not recognized by the attending physician at the time of admission. A recent study concerning the reasons for paediatric hospitalization (children under the age of 19) found that $2.09 \%$ of all paediatric hospitalizations were caused by ADRs and that $39 \%$ of these were life-threatening.

Added to this, half of these ADRs are not recognized by the physicians on admission and ADRs may be responsible for death of huge amount of patients. Furthermore, the financial cost of ADRs to the healthcare system is also vast. ${ }^{53}$ In market, when the new medicines are launched without long term safety studies by the regulatory authorities, patients follow the self medication and switching of prescription-only medicines (POM) to overthe-counter (OTC) more widely, and this is the main reason of exposing itself to ADRs. In the earlier period, India's regulatory agencies and drug companies based their safety assessments on experiences derived from long-term use. ${ }^{54}$ In recent years, many Indian companies are increasing the investment in research and development and are enhancing their capacity to develop and market new drugs with their own research efforts. Once a product is marketed, new information will be generated, which may have an impact on the benefit-risk profile of the product. The detailed evaluation of the new information generated through pharmacovigilance activities is important for all products to ensure their safe use.

India is a vast country and there is a excess of drug brands more than 6,000 licensed drug manufacturers and over 60,000 branded formulations. India is the fourth biggest producer of pharmaceuticals in the world and is also rising as a clinical trials hub. Many new drugs are being introduced in the country, so there is an immense need to improve the pharmacovigilance system to protect the Indian population from potential harm that may be caused by some of the new drugs. ${ }^{55}$

In India, a pharmaceutical company holding the marketing license should ensure that they have adequate pharmacovigilance system in place to ensure the responsibility and liability of their marketed products. When two or more marketed products are identical in all aspects except their trade names, each pharmaceutical company holding a marketing license is obliged to meet the pharmacovigilance obligations. ${ }^{56}$ This includes establishment and maintenance of appropriate pharmacovigilance system to collect and evaluate information about suspected adverse reactions.

\subsection{Future prospects}

As the future prospects a robust, pharmacovigilance system capable to detect new ADRs an, taking regulatory actions needed to protect public health. Little emphasis has been put into generating information that can assist a healthcare professional or a patient in the decision-making process. The gathering and communication of this 
information is an important goal of pharmacovigilance. ${ }^{57}$ Information about the safety of drug active surveillance is necessary. When developing new methods for active postmarketing surveillance, one has to keep in mind the importance of being able to gather information. Spontaneous reporting is a useful tool in generating signals, but the relatively low number of reports received for a specific association makes it less useful in identifying patient characteristics and risk factors. ${ }^{\mathbf{5 8}}$ Pharmacovigilance methods must also be able to describe which patients are at risk of developing an ADR. As a source of information pharmacovigilance approach would be consistent with the growing patient involvement in drug safety.

At present, the DCGI should act quickly to improve pharmacovigilance so as to integrate Good Pharmacovigilance Practice (GPP) into the processes and procedures to help ensure regulatory compliance and enhance clinical trial safety and post marketing surveillance. An appropriately working pharmacovigilance system is essential if medicines are to be used carefully. It will be benefit for healthcare professionals, regulatory authorities, pharmaceutical companies and the consumers. It helps pharmaceutical companies to monitor their medicines for risk. ${ }^{\mathbf{5 9}}$ Post-marketing pharmacovigilance is currently a challenging and laborious process, not only industry-wide, but also for regulatory agencies.

The aim of the pharmacovigilance is to receive the information, documentation of the work and knowledge online while giving priority to the new and important safety issues. Non-serious events have less priority than serious events, although they are also screened routinely. ${ }^{\mathbf{6 0}}$

\section{REFERENCE:}

1. Tripathi KD, Essentials of Medical Pharmacology, Jaypee Brothers Medical Publishers (P) Ltd. New Delhi; 2003. P. 202203.

2. Rang HP, Moore PK, Pharmacology, Elsevier, 2006, 2:122123 .

3. Nebeke JR, Clarifying adverse drug events: A clinician's guide to terminology, documentation and reporting, Ann Intern Med, 2004, 2:795-801.

4. Nebeker R, Barach P, Clarifying adverse drug events: A clinician's guide to terminology, documentation, and reporting, Ann Intern Med, 2004, 2:482-576.

5. Foley DJ, Wallace RB, Fulton MM, Polypharmacy in the elderly: A literature review, J Am Acad Nurse Pract, 2005; 7:123-132.

6. Prakash S, Pharmacovigilance in India, Indian J Pharmacol, 2007, 1:125-128.

7. Phillips KA, Veenstra DL, Oren E, Potential role of pharmacogenomics in reducing adverse drug reactions: A systematic review, JAMA, 2001, 4:2270-2279.

8. Goldstein DB, Pharmacogenetics in the laboratory and the clinic, N Engl J Med, 2003, 6:553-556.

9. Weinshilboum R, Inheritance and drug response, N Engl $\mathrm{J}$ Med, 2003, 6:529-537.

10. Evans WE, McLeod HL, Pharmacogenomics: Drug disposition, drug targets, and side effects, N Engl J Med, 2003, 6:538-549.

11. DeVane CL, Clinical significance of drug binding, protein binding, and binding displacement drug interactions, Psychopharmacol Bull, 2002, 2:5-21.
In present time, GSK has created a powerful new approach to pharmacovigilance, integrating traditional, case-based pharmacovigilance methods with dis-proportionality and data visualization tools. These tools exist within a system framework that facilitates in-stream review, tracking of safety issues and knowledge management. This very innovative tool and the processes will help to advance pharmacovigilance by improving efficiency and providing new analytical capabilities. ${ }^{[61]}$ Similar approach may be adopted by pharmaceutical companies for prompt detection and analysis of ADRs.

\section{CONCLUSION}

India is the fourth largest producer of pharmaceuticals and now emerging as an important clinical trial hub in the world. With introduction of new drugs, a robust pharmacovigilance system is need of the hour in our country to protect the population from the potential harm and adverse effect due to some of the new drug molecules. Pharmacovigilance plays a crucial role in meeting the challenges posed by the ever increasing range and potency of medicines. But the pharmacovigilance system in India is still not well developed. Despite of recent implementation of a well structured pharmacovigilance program in India in accordance with the objectives and recommendations of WHO by CDSCO, desired success is still a distant dream.

However increased awareness and training of public and medical professions, framing of strong regulations for reporting of ADRs, effective implementation and collaborative efforts between government, regulatory officials, pharmaceutical companies, health care professionals and patient may lead to an effective pharmacovigilance system in India to insure the availability of safe medicines to public.

12. Benet LZ, Hoener BA, Changes in plasma protein binding have little clinical relevance, Clin Pharmacol Ther, 2002, 4:115-121.

13. Haider SI, Johnell K, Thorslund M, Trends in polypharmacy and potential drug-drug interactions across educational groups in elderly patients Int J Clin Pharmacol Therap, 2007, 4:643653.

14. Boyd CM, Darer J, Boult C, Clinical practice guidelines and quality of care for older patients with multiple comorbid diseases: implications for pay for performance, JAMA, 2005, 2:716-724.

15. Weingart SN, Ship AN, Aronson MD, Confidential clinician reported surveillance of adverse events among medical in patients, J Gen Intern Med, 2000, 4:470-477.

16. Harmark L, Grootheest V, Pharmacovigilance: methods, recent developments and future perspectives, Eur. J Clin Pharmacol, 2008, 64:743-752.

17. Waller PC, Evans SJ, A model for the future conduct of pharmacovigilance, Pharmacoepidemiol Drug Saf, 2003, 2:17-29.

18. Kurz X, The Eudra Vigilance database of spontaneous adverse reactions as a tool for $\mathrm{H} 1 \mathrm{~N} 1$ vaccine safety monitoring, Pharmacoepidemiol Drug Saf, 2010, 19:330-331.

19. Blenkinsopp A, Patient reporting of suspected adverse drug reactions: A review of published literature and international experience, Br J Clin Pharmacol, 2007, 6:148156.

20. Langen, J, Adverse drug reaction reporting by patients in the Netherlands: Three years of experience, Drug Saf, 2008, $1: 515-524$. 
21. Norwood PK, Sampson AR, A statistical methodology for postmarketing surveillance of adverse drug reaction reports, Stat Med, 1988, 7:1023-1030.

22. Evans SJ, Use of proportional reporting ratios for signal generation from spontaneous adverse drug reaction reports, Pharmacoepidemiol Drug Saf, 2001, 10:483-486.

23. Bate A, Evans SJ, Quantitative signal detection using spontaneous ADR reporting, Pharmacoepidemiol Drug Saf, 2009, 1:427-436.

24. Hauben M, Application of an empiric Bayesian data mining algorithm to reports of pancreatitis associated with atypical antipsychotics, Pharmacotherapy, 2004, 2:1122-1129.

25. Lindquist M, From association to alert a revised approach to International Signal Analysis, Pharmacoepidemiol Drug Saf, 1999, 8:15-25.

26. DuMouchel, Pregibon D, Empirical Bayes screening for multi item associations, International Conference on Knowledge Discovery and Data Mining, 2001, 3:67-76.

27. Strom BL, Overview of automated databases in pharmacoepidemiology (ed). Pharmacoepidemiology Chichester, UK, John Wiley \& Sons,2005: P. 219-222.

28. Herret E, Validation and validity of diagnoses in the general practice research database: A systematic review, J Clin Pharmacol, 2010, 9:4-14.

29. Abenhaim L, Appetite-suppressant drugs and the risk of primary pulmonary hypertension, N Engl J Med, 1996, 3:609616.

30. Roujeau JC, Medication use and the risk of Stevens Johnson syndrome or toxic epidermal necrolysis, N Engl J Med, 1995, 3:1600-1608.

31. Kaufman DW, Signal generation and clarification: Use of case-control data, Pharmacoepidemiol Drug Saf, 2001, 10:197-203.

32. Butlen S, Ducuing F, European medicines agency support mechanisms fostering orphan drug development, Drug News Perspect, 2010; 23:71-81.

33. Giezen TJ, Evaluation of post-authorization safety studies in the first cohort of EU risk management plans at time of regulatory approval, Drug Saf ,2009, 32:1175-1187.

34. Iskander $\mathrm{J}$, Monitoring vaccine safety during an influenza pandemic, Yale J Biol Med, 2005, 78:261-271.

35. Stefano F, Tokars J. H1N1 vaccine safety monitoring: Beyond background rates. Lancet, 2010, 37:1146-1147.

36. Chen RT, The vaccine safety datalink: Immunization research in health maintenance organizations in the USA, Bull World Health Organ, 2010, 78:186-194.

37. Vander H, Stichele R, European Surveillance of Antimicrobial Consumption (ESAC): Data collection performance and methodological approach, Br J Clin Pharmacol, 2004, 58:419428.

38. Martirosyan LA, Systematic literature review: Prescribing indicators related to type 2 diabetes mellitus and cardiovascular risk management, Pharmacoepidemiol Drug Saf, 2010, 19:319-334.

39. Von NC, Schwappach DL, Koeck CM, The epidemiology of preventable adverse drug events: A review of literature, Wien Klin Wochenschr, 2003, 12:407-415.

40. $\mathrm{Wu} \mathrm{WK}$, Pantaleo N, Evaluation of outpatient adverse drug reactions leading to hospitalization, Am J Health Syst Pharm, 2003, 13:253-259.

41. Gautier S, Bachelet H, Bordet R, Caron J, The cost of adverse drug reactions, Expert Opin Pharmacother, 2003, 3:319-326.

42. Muehlberger N, Schneeweiss S, Hasford J, Adverse drug reaction monitoring cost and benefit considerations. Part I: Frequency of adverse drug reactions causing hospital admission, Pharmacoepidemiol Drug Saf, 1997, 3:71-77.
43. Muehlberger N, Schneeweiss S, Hasford J, Adverse drug reaction monitoring cost and benefit considerations. Part II: Cost and preventability of drug reactions leading to hospital admission, Pharmacoepidemiol Drug Saf, 1997, 3:79-90.

44. Kanjanarat P, Winterstein AG, Johns TE, Hatton RC, Nature of preventable adverse drug events in hospital: A literature review, Am J Health Syst Pharm, 2003, 17:1750-1759.

45. Moride Y, Haramburu F, Requejo A, Begaud B. Underreporting of adverse drug reactions in general practice, $\mathrm{Br} \mathrm{J}$ Clin Pharmacol, 1997, 2:177-181.

46. Cosentino M, Leoni O, Banfi F, Lecchini S, Frigo G, Attitudes to adverse drug reaction reporting by medical practitioners in a northern Italian district, Pharmacol Res, 1997, 2:85-88.

47. Tripathy R, Basha S, Jain R, Shetty S , Ramachandran A, Exenatide and acute pancreatitis, J Assoc Physician India, 2008, 56:987-988.

48. Meslin EM, Protecting human subjects from harm through improved risk judgments, IRB 1990, 12:7-10.

49. King NM, Churchill LR, Assessing and comparing potential benefits and risks of harm, The Oxford Textbook of Clinical Research Ethics. In: Emanuel E, Grady C, Crouch RA, Lie RA, Miller FG, Wendler D editors. New York: Oxford University Press; 2008. pp. 514-526.

50. Rid A, Emanuel EJ, Wendler D, Evaluating the risks of clinical research, JAMA, 2010, 304:1472-1479.

51. Garrard E, Dawson A, What is the role of the research ethics committee? Paternalism, inducements, and harm in research ethics, J Med Ethics, 2005, 31:419-423.

52. Jonas $\mathrm{H}$, Philosophical reflections on experimenting with human subjects, Daedalus, 1969, 98:219-247.

53. Kalantri SP, Ethics in clinical research, Indian J Anaesth, 2003, 47:30-32

54. Grady C, Payment of clinical research subjects. J Clin Invest, 2005, 115:1681-1687.

55. Food and Drug Administration. Guidance for Industry and Investigators: Safety Reporting Requirements for IND and BA/BE studies. Draft guidance.2010. Available from: http://www.fda.gov/downloads/Drugs/GuidanceComplianceRe gulatoryInform ation/Guidances/UCM227351.pdf. [Accessed on 2010 Dec 10].

56. International Conference on Harmonization of Technical Requirements for Registration of Pharmaceuticals for Human Use. Guideline for Good Clinical Practice E6.1996. Available from: http:// www.ich.org/LOB/media/MEDIA482.pdf. [Accessed on 2010 Dec 10].

57. International Conference on Harmonization of Technical Requirements for Registration of Pharmaceuticals for Human Use. Development Safety Update Report E2F. 2010. Available from: http:// www.ich.org/LOB/media/MEDIA4727.pdf. [Accessed on 2010 Dec 10].

58. Food and Drug Administration. Code of Federal Regulations Title 21. Sec. 312.33 IND Annual Reports. 2010. Available from: http://www.accessdata.fda.gov/scripts/cdrh/ cfdocs/cfcfr/CFRSearch. $\mathrm{cfm}$ ?fr= 312.33. [Accessed on 2010 Dec 10].

59. European Commission. Detailed Guidance on the Collection, Verification and Presentation of Adverse Reaction Reports Arising from Clinical Trials on Medicinal Products for Human Use. 2006. Available from: http://ec.europa.eu/health/files/ eudralex/vol-10/21 [Accessed on 2010 Dec 10].

60. International Conference on Harmonization of Technical Requirements for Registration of Pharmaceuticals for Human Use. Final Concept Paper- E2F-Development Safety Update Report. 2006. Available from: http://www.ich.org/LOB/media/MEDIA 3302.pdf. [Accessed on 2010 Dec 10]. 